\title{
After the break: DSB end processing in mouse meiosis
}

\author{
Kevin Brick, Florencia Pratto, and R. Daniel Camerini-Otero \\ Genetics and Biochemistry Branch, National Institute of Diabetes and Digestive and Kidney Diseases, National Institutes of \\ Health, Bethesda, Maryland 20892, USA
}

The exchange of genetic information between parental chromosomes in meiosis is an integral process for the creation of gametes. To generate a crossover, hundreds of DNA double-strand breaks (DSBs) are introduced in the genome of each meiotic cell by the SPO11 protein. The nucleolytic resection of DSB-adjacent DNA is a key step in meiotic DSB repair, but this process has remained understudied. In this issue of Genes \& Development, Yamada and colleagues (pp. 806-818) capture some of the first details of resection and DSB repair intermediates in mouse meiosis using a method that maps blunt-ended DNA after ssDNA digestion. This yields some of the first genome-wide insights into DSB resection and repair in a mammalian genome and offers a tantalizing glimpse of how to quantitatively dissect this difficult to study, yet integral, nuclear process.

The repair of meiotic DSBs by homologous recombination (HR) assures the exchange of genetic material between parental haplotypes in the germline (for review, see Lam and Keeney 2015). One of the early steps in meiotic DSB repair is the nucleolytic resection of $5^{\prime}$ DNA at the break site to produce a $3^{\prime}$ ssDNA overhang. Recombinase proteins (DMC1, RAD51, and others) bind the exposed $3^{\prime}$ ssDNA, creating a nucleoprotein filament capable of performing a homology search to identify the allelic locus on the other parental chromosome. Subsequent strand invasion displaces a loop of DNA (D-loop) to begin the process of DSB repair. The underlying mechanisms of resection are likely to govern how this homology search and repair are facilitated; however; this integral aspect of DNA repair in mammals remains remarkably poorly understood.

Now, Yamada et al. (2020) from the Keeney laboratory at Memorial Sloan Kettering Cancer Center give us some of the first insights into this process in mammalian meiosis. They used a method pioneered in yeast to digest all ssDNA at DSB hot spots undergoing repair (Mimitou

[Keywords: meiosis; recombination; DNA double-strand breaks; resection; EXO1; ATM; PRDM9; chromatin]

Corresponding author: rdcamerini@mail.nih.gov

Article is online at http://www.genesdev.org/cgi/doi/10.1101/gad.339309. 120 . et al. 2017). Subsequently, the resulting blunt-ended DNA products, which derive mostly from the endpoints of resection, are captured and sequenced. This adds a powerful and sensitive new tool to our arsenal for better understanding the intricate molecular intermediates that form during recombination.

The signal from S1-seq experiments is predominantly derived from the endpoints of resection (Fig. 1), allowing the investigators to show that average resection length in mouse male meiosis is $\sim 1.1 \mathrm{~kb}$. This is substantially longer than previous best estimates of resection length derived from mapping DMC1-bound ssDNA (Lange et al. 2016); thus, it appears that the DMC1 protein does not extend all the way to the $5^{\prime}$ end of resected DNA. Examining the protein(s) that occupy the $5^{\prime}$ end of resected DNA will be a key direction for future work. Resection length in mice is remarkably similar to resection length in baker's yeast, despite the differences in genome size and compaction; it will be interesting to see what governs this conservation. Studying genetic knockouts is particularly challenging for mammalian recombination; however; because S1-seq is highly sensitive, the investigators were able to explore the genetic determinants of resection length. Surprisingly, the major resection exonuclease in yeast (EXO1) was shown to play only a minimal role in regulating resection tract length in mice. This implies that resection is mechanistically distinct in mammals, opening the door to future studies of how these processes differ. They also discovered genetic factors shared between mice and yeast: The $\mathrm{DMCl}$ protein is required to limit resection tract length, evoking a link between DSB repair proteins and the resection machinery. Most substantially, mice lacking the ATM kinase (tell in yeast) exhibited both perturbed initiation and extension of resection. Unresected DSBs were also detected in these mice (Fig. 1), though not in wild type. This unexpected dual role of ATM, coupled with its role in regulating DSB frequency (Lange et al. 2011), establishes ATM as a multifaceted regulator of meiotic recombination. DNA resection endpoints in yeast exhibited a clear dependency on nucleosome locations with S1-seq endpoints occurring primarily in between nucleosomes (Mimitou et al. 2017). Surprisingly, this dependency was not seen in mice. Whether this difference stems from the reduced

This is a work of the US Government. 


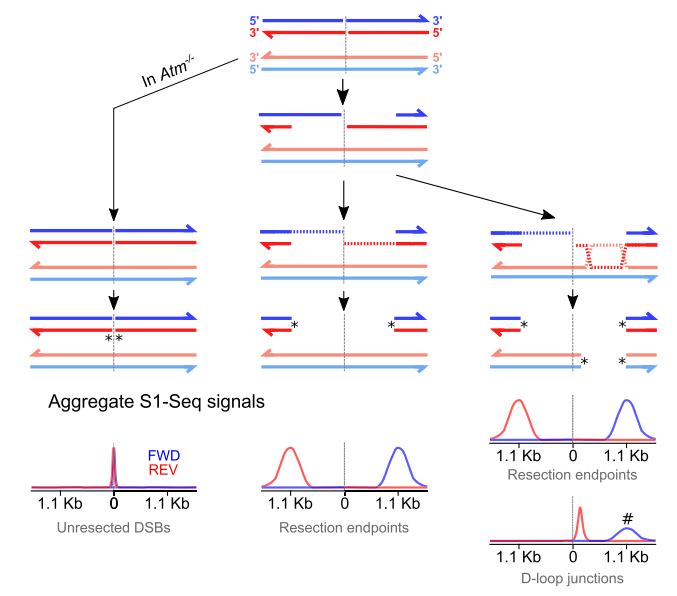

Figure 1. S1-seq captures intermediates of meiotic DSB repair. Meiotic DSBs are formed by the Spol1 protein. In wild type, DNA around the DSB is resected to reveal $3^{\prime}$ ssDNA overhangs. S1-seq entails an initial step of S1 endonuclease digestion. This will digest ssDNA at DNA undergoing recombination (dashed lines). The resulting blunt-ended products can be sequenced following end repair and adapter ligation (asterisks). (Left panel) In $\mathrm{Atm}^{-1-}$ mice, unresected DSBs are detected as an S1-seq signal at the DSB site. This differs from the signal from D-loop junctions, which is displaced from the center by tens of base pairs. The theoretical aggregate S1-seq signals in a population of cells are shown below. (\#) The distribution of the DSB-distal D-loop end points is assumed to follow that of resection endpoints.

dependence on EXO1 in mouse meiosis remains to be seen, as detecting this type of dependency in mammalian genomes can be challenging. Indeed, while yeast DSBs occur in the context of constitutively phased nucleosome arrays (Pan et al. 2011), the chromatin at mouse DSB hot spots is actively remodeled (Spruce et al. 2020; Yamada et al. 2020).

Perhaps the investigators' most intriguing result came from a signal derived not from resection endpoints, but from the apparent capture of a previously undocumented recombination intermediate, displaced by tens of nucleotides from the site of the DSB. (Fig. 1) This intermediate in yeast is either not evident from S1-seq, or is more dispersed, as recombination intermediates span a far broader region (Mimitou et al. 2017). Cleverly leveraging strand information from their sequencing strategy and genetic knockouts, the investigators demonstrate that the captured intermediate is most likely the D-loop junction on the invaded chromosome. Intriguingly, the signal from the intermediate is absent at sex chromosome hot spots. Given that DSBs on sex chromosomes in males are repaired from the sister chromatid, this could imply that the intermediate is a reflection of interhomolog, but not intersister, repair. Nonetheless, S1-seq can detect intermediates from intersister repair events in F1 hybrids. Therefore, it appears that the presence of the homolog, but not necessarily interhomolog repair, is required to capture the intermediate. The location and polarity of the S1-seq signal imply that the $3^{\prime}$ end of the ssDNA is not participating in the strand invasion reaction. This raises the possibility that SPO11 remains bound, an idea put forward previously by these investigators and others (Neale et al. 2005; Paiano et al. 2020). This enticing model with SPO11 remaining attached to the $3^{\prime}$ end of resected DNA would also offer a mechanism to reverse course if HR were unsuccessful; gap repair primed from the SPO11-attached oligo could allow repair by other methods, such as nonhomologous end joining.

Overall, this work and another similar approach published recently (Paiano et al. 2020) open a fascinating portal into a previously opaque process and a plethora of new avenues of research. Future studies to ask whether SPO11 indeed remains attached, to understand the requirements for the newly discovered recombination intermediates, and to ask why these intermediates may differ from those in yeast will undoubtedly help us to better understand this critical DNA repair process.

\section{References}

Lam I, Keeney S. 2015. Mechanism and regulation of meiotic recombination initiation. Cold Spring Harb Perspect Biol 7: a016634. doi:10.1101/cshperspect.a016634

Lange J, Pan J, Cole F, Thelen MP, Jasin M, Keeney S. 2011. ATM controls meiotic doublestrand-break formation. Nature 479: 237-240. doi:10.1038/nature 10508

Lange J, Yamada S, Tischfield SE, Pan J, Kim S, Zhu X, Socci ND, Jasin M, Keeney S. 2016. The landscape of mouse meiotic double-strand break formation, processing, and repair. Cell 167: 695-708.e16. doi:10.1016/j.cell.2016.09.035

Mimitou EP, Yamada S, Keeney S. 2017. A global view of meiotic double-strand break end resection. Science 355: 40-45. doi:10 $.1126 /$ science.aak9704

Neale MJ, Pan J, Keeney S. 2005. Endonucleolytic processing of covalent protein-linked DNA double-strand breaks. Nature 436: 1053-1057. doi:10.1038/nature03872

Paiano J, Wu W, Yamada S, Sciascia N, Callen E, Paola Cotrim A, Deshpande RA, Maman Y, Day A, Paull TT, et al. 2020. ATM and PRDM9 regulate SPO11-bound recombination intermediates during meiosis. Nat Commun 11: 857. doi:10.1038/ s41467-020-14654-w

Pan J, Sasaki M, Kniewel R, Murakami H, Blitzblau HG, Tischfield SE, Zhu X, Neale MJ, Jasin M, Socci ND, et al. 2011. A hierarchical combination of factors shapes the genome-wide topography of yeast meiotic recombination initiation. Cell 144: 719-731. doi:10.1016/j.cell.2011.02.009

Spruce C, Dlamini S, Ananda G, Bronkema N, Tian H, Paigen K, Carter GW, Baker CL. 2020. HELLS and PRDM9 form a pioneer complex to open chromatin at meiotic recombination hot spots. Genes Dev 34: 398-412. doi:10.1101/gad.333542 .119

Yamada S, Hinch AG, Kamido H, Zhang Y, Edelmann W, Keeney S. 2020. Molecular structures and mechanisms of DNA break processing in mouse meiosis. Genes Dev (this issue). doi:10 $.1101 / \operatorname{gad} .336032 .119$ 


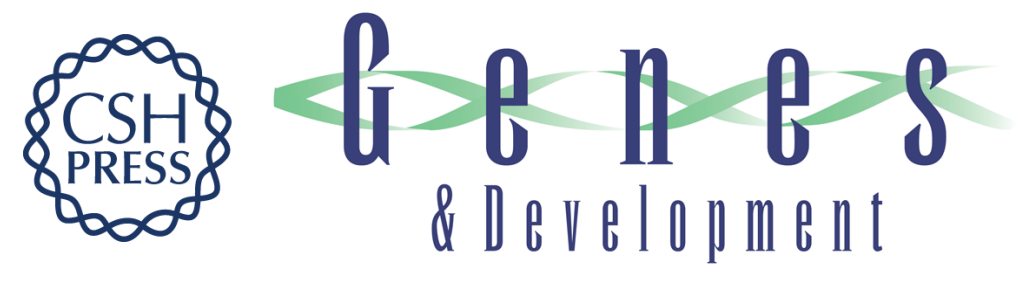

\section{After the break: DSB end processing in mouse meiosis}

Kevin Brick, Florencia Pratto and R. Daniel Camerini-Otero

Genes Dev. 2020, 34:

Access the most recent version at doi:10.1101/gad.339309.120

Related Content Molecular structures and mechanisms of DNA break processing in mouse meiosis Shintaro Yamada, Anjali Gupta Hinch, Hisashi Kamido, et al. Genes Dev. June , 2020 34: 806-818

References This article cites 9 articles, 4 of which can be accessed free at: http://genesdev.cshlp.org/content/34/11-12/731.full.html\#ref-list-1

Articles cited in: http://genesdev.cshlp.org/content/34/11-12/731.full.html\#related-urls

License This is a work of the US Government.

Email Alerting Receive free email alerts when new articles cite this article - sign up in the box at the top Service right corner of the article or click here.

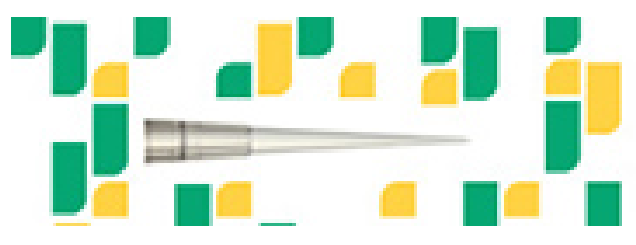

Focused on your science. 